\title{
Palliative care in long term care institutions for the elderly in Brazil: a necessary investment
}

Keywords: long term care, philosophy, elderly, palliative care

\section{Introduction}

This opinion article aims to discuss the philosophy of palliative care in Long Term Care Institutions for elderly people in Brazil. The author uses her 12 years professional experience and the research on the subject which was part of her Doctoral Dissertation accomplished in 2016 .

\section{Thinking about care}

Long Term Care Institutions that welcome elderly are essentially contradictory. They represent places for care, comfort and safety. In the other hand they are also spaces of segregation, disruption and loss. Since most institutions upkeep their residents until the last day of their lives, to live and die in these places are the daily challenges facing the residents. Although they exist for a long time, palliative care is still a challenge.

In the context of Brazilian institutions, it is possible identify what it can called "speech affection": a subjective strategy used by professionals and family members to make up for the lack of knowledge about palliative care, poor physical infrastructure and limited financial resources. This speech is manifested in expressions "I like old people", "I work for love." Unfortunately, the institutional routine philosophy of palliative care, as part of decent care, individualized and focused on the subject, does not guide daily practices. ${ }^{2-4}$

The impact of the lack of palliative care in Brazilian institutions is perceived from three dimensions: structural, due to the lack of material and financial resources; human resources, perceived by the fragility of the technical knowledge of the professionals, where most are recent graduates, without specific training in the care of elderly not in palliative care; ethical-moral, materialized through a set of value judgments that lead guided decisions on moral values and/or religious beliefs that hinder centered care in the best interests of the elderly.

Based on a research conducted in 2016, ${ }^{1}$ care at the end of life for institutionalized elderly is focus on curative aims - often not humanized, not having an alleviation of suffering prospect not focus on death with dignity. It means to say that the facilities for the elderly in Brazil are not structured to recognize the needs of care to ensure comfort and dignity in the dying process of their patients. In a social context marked by deep social inequalities and health, there is a strong relationship between the economic dimension and the dimension of care, especially the tendency to commercialization of this process. Human care, in that it becomes a necessity for the elderly and families, becomes product to be exploited economically.

\section{Conclusion}

The research of the doctoral dissertation allowed me the following
Volume 2 Issue I - 2018

\author{
Michelle Bertoglio Clos \\ Department of Social Work, Lutheran University of Brazil, Brazil
}

Correspondence: Michelle Bertoglio Clos, Av. Monte Cristo, 100, casa I8, Porto Alegre, Brazil, Tel 555 I 995046005 , Email michelleclos@gmail.com

Received: December 04, 2017 | Published: January 02, 2018

conclusion: palliative care and care at end of life is not meant to shorten life, but extends it with quality, but there is still a long way in Brazil for understanding these concepts, that result in an appropriate policy context of institutions for the elderly. A proposal possible in implementing the philosophy of palliative care in the context of institutions includes: professional training, appropriate structures care and review of ethical and moral values of work group and family about the process of dying with dignity. For this to happen we need to invest in accurate diagnoses, pain management, multidisciplinary care, opportunities for farewell. Elder and family, custom environments, respect for the biography of the subjects, understanding of the importance of body touch, appropriateness of language for dialogue with the family and the elderly, to invest in religious beliefs and CAM (Complementary and alternative medicine).

\section{Acknowledgements}

None.

\section{Conflict of interest}

The author declares no conflict of interest.

\section{References}

1. Clos, MB. Care at the end of the life of institutionalized elders: contradictions and challenges/Michelle Bertóglio Clos; Counselor Patricia Krieger Grossi. Porto Alegre, Brazil: Springer; 2006. 149 p.

2. Trotta RL. Quality of death: a dimensional analysis of palliative care in the nursing home. J Palliat Med. 2007;10(5):1116-1127.

3. Hanson LC, Henderson M, Menon M. As individual as death itself: a focus group study of terminal care in nursing homes. $J$ Palliat Med. 2002;5(1):117-125.

4. Hall S, Kolliakou A, Petkova H, et al. Interventions for improving palliative care for older people living in nursing care homes. Cochrane Database Syst Rev. 2011;(3):CD007132. 